\title{
A ENFERMAGEM NA ASSISTÊNCIA AO INDIVÍDUO EM SOFRIMENTO PSÍQUICO*
}

\author{
Rosa Maria Rodrigues** \\ Jacó Fernando Schneider***
}

RODRIGUES, R.M.; SCHNEIDER, J.F. A enfermagem na assistência ao indivíduo em sofrimento psíquico. Rev.latinoam.enfermagem, Ribeirão Preto, v. 7, n. 3, p. 33-40, julho 1999.

\begin{abstract}
A assistência de enfermagem ao ser humano em sofrimento psíquico é o tema desta pesquisa, desenvolvida num hospital psiquiátrico na região oeste do Paraná. Trata-se de uma pesquisa qualitativa com o objetivo de levantar a compreensão que tem o enfermeiro acerca do seu fazer na enfermagem psiquiátrica. Utilizou-se a entrevista aberta abrangendo todos os enfermeiros da instituição, onde os dados foram agrupados em unidades temáticas e analisados através da análise de conteúdo.
\end{abstract}

UNITERMOS: assistência de enfermagem, enfermagem psiquiátrica

\section{APRESENTAÇÃO}

Sem querermos levantar aqui toda a discussão acerca do processo de desinstitucionalização da psiquiatria, que reflete diretamente na assistência em enfermagem psiquiátrica, pensamos ser possível no espaço institucional, implementar uma assistência mais comprometida com o ser humano, com a sua cidadania.

Ao refletirmos sobre o trabalho da enfermagem em hospitais psiquiátricos perguntamo-nos se é só o que encontramos nestas instituições o que deveríamos fazer, como por exemplo, a supervisão do trabalho do pessoal auxiliar de enfermagem, $o$ atendimento de intercorrências psiquiátricas, os encaminhamentos para outros membros da equipe, o controle de material e do ambiente físico e a realização de relatórios e registros das atividades e intercorrências, ou, se a assistência de enfermagem poderia ter outras modalidades, visto que, não raro surgem os mais diversos problemas com pacientes devido à falta de contato do enfermeiro com os mesmos. Estes problemas que se apresentam dizem respeito à pacientes com psicose puerperal, com mamas ingurgitadas, com curativos esquecidos, isolados há dias sem nenhuma solução, entre outros.
Frente a isso, pensamos serem as questões da vida prática que nos devem impulsionar a buscar explicações e formular soluções para melhorarmos nossa prática profissional, sendo este um momento em que possamos entender os determinantes dessa prática assistencial em psiquiatria, visto que vivenciamos uma realidade nessa área, o que nos deu subsídios para refletirmos sobre uma proposta diferente.

Neste sentido, a proposta deste estudo é identificar qual a compreensão que o enfermeiro que trabalha em psiquiatria tem sobre o seu trabalho.

\section{A ENFERMAGEM PSIQUiÁtRICA NO BRASIL}

Gostaríamos de apontar que quando estivermos tratando da enfermagem psiquiátrica, pretendemos estar pensando nela em um contexto maior, ou seja, vinculada com as relações sociais, políticas e econômicas que estarão permeando suas práticas. Sobre isso, FRAGA (1993, p.17) coloca que "a enfermagem é uma prática histórica e social e como tal liga-se à realidade subjetiva

\footnotetext{
* Trabalho adaptado da monografia de especialização "Assistência de enfermagem ao ser humano em sofrimento psíquico", orientada pelo Professor Jacó Fernando Schneider, apresentada ao Departamento de Enfermagem da Universidade Estadual do Oeste do Paraná, em novembro de 1997

** Enfermeira, Especialista em Enfermagem em Saúde Pública, Docente do Departamento de Enfermagem da Universidade Estadual do Oeste do Paraná. Mestranda do Programa de Enfermagem Fundamental da Escola de Enfermagem de Ribeirão Preto da Universidade de São Paulo

*** Enfermeiro, Mestre em Enfermagem Psiquiátrica, Docente do Departamento de Enfermagem da Universidade Estadual do Oeste do Paraná. Doutorando do Programa Interunidades de Doutoramento em Enfermagem da Escola de Enfermagem de Ribeirão Preto da Universidade de São Paulo
} 
dos que a executam e às suas condições materiais de existência".

Ao resgatarmos o contexto histórico em que a enfermagem psiquiátrica surge, observamos que no período de início da enfermagem psiquiátrica, o trabalho estava vinculado as ordens religiosas, que organizavam todo o ambiente do hospício e que faziam o papel de supervisão, havendo um abuso de poder por parte destas religiosas que encobriam e permitiam maus tratos aos doentes.

No entanto, após a proclamação da República, em 1889 , o poder das religiosas começa a diminuir, enfraquecendo assim suas atribuições, sendo o momento em que as mesmas deixam as instituições.

Com o abandono do hospício pelas religiosas, o Governo Provisório da República manda buscar, na França, enfermeiras leigas para continuar nas funções de organização do hospício, sendo que elas deveriam organizar uma escola para enfermeiros no Hospício Nacional de Alienados. Esta é a primeira tentativa de formalizar o ensino da enfermagem no Brasil, só que no modelo religioso, pois o "ensino de enfermagem francês ainda se baseava no modelo religioso não tendo aderido ainda ao sistema Nightingale" (ROCHA, 1994, p.8).

A enfermagem psiquiátrica, dentro do contexto que se desenhou, foi e é tratada em caráter secundário, pois o doente mental é tido como improdutivo, incômodo e que ainda impede que os outros produzam, como é o caso da família.

No período atual, onde a enfermagem está sendo influenciada pelo referencial das relações humanas, o enfoque deixa de ser apenas o aspecto físico/biológico da doença, passando a ser considerada no contexto de relações do paciente, relação "com outras pessoas", onde o enfermeiro estaria explorando o seu "ser" profissional como instrumento de assistência.

A forma como isto se manifestou, na prática, foi a postura do enfermeiro enquanto "psicoterapêuta", através do "relacionamento terapêutico". Este posicionamento teve sua impulsão com o trabalho de Peplau, que salienta que a essência do trabalho do enfermeiro seria o desenvolvimento dessa habilidade, que deve ser adquirida através do conhecimento formal sobre aconselhamento, para ser utilizada como forma de abordagem com o paciente (ROCHA, 1994).

Esta concepção do trabalho do enfermeiro é criticada no sentido de que não considera o mundo de relações do ser com sofrimento mental, mundo este que é mais que relações interpessoais, é relação de classe, de sobrevivência, de auto-reprodução de sua vida material e social.

Por outro lado, esta percepção introduziu um novo enfoque no trabalho do enfermeiro. Se antes a atenção estava totalmente voltada para os aspectos biológicos da doença, este posicionamento possibilitou introduzir a interação efetiva entre enfermeiro e paciente como parte importante do trabalho daquele.

Mesmo sendo o relacionamento interpessoal a essência do trabalho da enfermagem psiquiátrica, ele não é realizado efetivamente. Segundo AGUIAR (1995, p.21): "O cumprimento de normas burocráticas coloca-se como objeto central do trabalho da enfermeira".

Parece que a mudança no discurso nem sempre acompanha alterações na atividade concreta. Acreditamos que estas mudanças estejam muito vinculadas ao caráter de cronicidade da doença mental, ao estigma que consequentemente torna o doente incapaz de interagir na sociedade ou voltar a ser produtivo.

Sendo o doente mental considerado apenas um peso na sociedade, não há porque se implementar medidas de prevenção ou de tratamento, daí o caráter confinador dos tratamentos psiquiátricos. No entanto, neste momento em que se fala em substituição do ambiente hospitalar, ou das instituições totais, é oportuno rever qual o papel da enfermagem e do enfermeiro neste contexto.

A enfermagem psiquiátrica, inserida no contexto social e coadjuvante com outras práticas sociais tem determinações muito precisas, em contextos específicos. Estas determinações, possibilitaram um modelo de "assistência de enfermagem" carcerário, disciplinador, mantenedor da ordem. Urge encontrar uma alternativa à este quadro. Esta alternativa terá que ser construída coletivamente, sendo as reflexões explicitadas em trabalhos desta área, elementos que podem contribuir para esse processo de mudanças.

\section{TRAJETÓRIA METODOLÓGICA}

Nossa tentativa neste estudo, será através dos discursos dos enfermeiros, identificar o que eles têm compreendido como sendo enfermagem psiquiátrica e como tem sido sua prática. Para tanto, a pesquisa qualitativa será o embasamento deste estudo.

\section{O Local da Pesquisa}

O campo onde se realizou esta pesquisa foi o Hospital e Casa de Saúde São Marcos, de Cascavel. Tratase de uma instituição privada que presta serviços ao SUS, atuando na área de psiquiatria.

\section{Os Sujeitos Participantes da Pesquisa}

Uma vez que teremos como núcleo dos questionamentos a compreensão que o enfermeiro tem do que seja o seu saber/fazer em enfermagem psiquiátrica, 
os sujeitos entrevistados foram sete enfermeiros que estão no trabalho diário com os pacientes na referida instituição.

\section{Coleta de Dados}

Os dados foram coletados através de depoimentos dos enfermeiros, sendo para tanto utilizado a entrevista gravada e transcrita posteriormente na íntegra.

Antes de iniciarmos a coleta de dados solicitamos a instituição, através de ofício, permissão para a realização das entrevistas na mesma.

As entrevistas foram coletadas nos horários em que os enfermeiros estavam em serviço. Assim, um dos autores desse estudo se dirigiu ao local em todos os turnos de trabalho, sendo que o contato com os entrevistados foi feito com antecedência, onde ocorreu a comunicação sobre o anonimato dos participantes.

Em função da natureza do objeto investigado neste trabalho, parece-nos que a entrevista permitiu coletar uma maior amplitude de dados, enriquecendo os mesmos. Assim, utilizamos como modalidade a "entrevista não-estruturada ou aberta", com uma questão que norteou a mesma.

Para tanto, a questão que norteou a entrevista foi a seguinte: "como você vê o seu trabalho em enfermagem psiquiátrica?".

\section{ANÁLISE DOS DADOS}

Os dados coletados foram transcritos na sua íntegra e agrupados por convergência de conteúdo. Assim, eles foram lidos várias vezes, resultando em sete unidades temáticas, que apareceram através da repetição de conteúdos na fala dos enfermeiros entrevistados, sendo agrupadas e analisadas através da análise de conteúdo (BARDIN, 1991).

Para a referida autora, a análise de conteúdo é uma técnica de pesquisa social utilizada para realizarmos uma descrição objetiva das informações dos sujeitos, tendo como meta a interpretação destes discursos.

Para tanto, a análise de conteúdo foi desenvolvida em três fases: a) pré-análise; b) exploração do material; e c) tratamento e interpretação dos dados.

\section{Temáticas Identificadas nas Informações}

Para analisar as informações contidas nos discursos dos enfermeiros que atuam em psiquiatria, passamos a apresentar as falas - identificadas com o número do depoimento - que convergiram nas temáticas que seguem:
1. Para o enfermeiro, trabalhar na psiquiatria, é estar atendendo situações de emergência

"Realmente a gente tá sendo enfermeiro-bombeiro, né? Apagando um foguinho aqui, outro foguinho ali',D1

“(...) a gente, faz muito correndo prá cima e prá baixo, o dia todo apagando fogo, né? É uma das questões ver, sei lá, as queixas dos pacientes, atendendo paciente agitado, paciente agressivo $(\ldots)^{\text {, D3 }}$.

“(...) a gente tá mais atuando, como assim, apagando fogueira (...) a gente vê que não tem uma proposta voltada prá psiquiatria. A gente tá mais em cima de atendimento de ocorrência, né? Avaliando ocorrência e na supervisão dos funcionários" ${ }^{\text {D5 }}$.

2. O enfermeiro que trabalha com psiquiatria tem dificuldade em definir o que seja o seu trabalho, ou o seu papel dentro da enfermagem psiquiátrica

"Você chega num ponto que você pára e pensa, meu Deus! O quê que eu tô fazendo aqui. Qual que é o meu papel, eu tô desenvolvendo alguma coisa $(\ldots)^{\text {D1 } 1 \text {. }}$.

"Eu não sinto o nosso papel definido aqui no hospital. Não sinto mesmo, eu acho assim, que a gente tem muito o que fazer aqui (...) acho que a enfermagem não assumiu ainda o papel dela aqui nesse hospital, como deveria assumir, ${ }^{\mathrm{D} 4}$.

“(...) nós paramos muito pouco prá questionar, prá analisar, prá ver o que que a gente realmente tá querendo com a psiquiatria, né?"D3.

“(...) a gente já tá até conseguindo ver isso(...) A necessidade de definir, né? Qual que é o papel do enfermeiro dentro da psiquiatria (...), ${ }^{\text {,D6 }}$.

3. O enfermeiro percebe como conflitante a sua relação com a equipe técnica, onde não há limites definidos da especificidade do trabalho de cada um

“(...) a enfermagem na equipe técnica não tem muito valor ... eles não dão muito valor. Cobram muito da enfermagem (...), ${ }^{\text {,D4 }}$.

"Tem a questão, a equipe, a gente não quer entrar no espaço do outro, né? É...porque determinada coisa, a gente acha que é do psicólogo ou acha que é do terapeuta ocupacional, outra coisa é coisa específica do psiquiatra, então a gente tem essa dificuldade, né?"D2

"A gente tenta conversar muito com o paciente, né?

Mas, como aqui é uma equipe, multiprofissional: psicólogo, terapeuta, assistente social às vezes, o enfermeiro acaba deixando essa parte só prá eles"D1.

4. O enfermeiro atribui à formação acadêmica sua dificuldade em trabalhar com o paciente em sofrimento psíquico

"A formação, talvez, foi um tanto teórica, talvez é desvinculada do que acontece nos hospitais 
psiquiátricos, embora não conhecendo outros, eu penso que a realidade de que a faculdade passa e o que a gente faz no hospital psiquiátrico, o espaço que dão prá gente, talvez exista uma pequena diferença entre eles (...) ${ }^{\text {,D2 }}$.

"Eu sinto que a faculdade não me preparou prá ser uma enfermeira em hospital psiquiátrico. (...) nos primeiros dias quando eu comecei a trabalhar tinha aquela coisa do medo que eu sentia na faculdade" ${ }^{\text {D4 }}$.

5. As questões administrativas estão presentes no discurso do enfermeiro como atividade que ele realiza na enfermagem psiquiátrica

"Então em psiquiatria eu vejo isso, se preocupar com a falta ou não de funcionários, com escala",D3 .

"A gente tá mais em cima de atendimento de ocorrências, né? Avaliando ocorrência e na supervisão dos funcionários" ${ }^{\text {D6 }}$.

“(...) tem toda a parte administrativa que é ao mesmo tempo que você vai zelar para estabelecer um relacionamento terapêutico, você vai ter que administrar sua equipe (...), ${ }^{\text {D5 }}$.

6. Quando o enfermeiro estabelece relação entre o trabalho no hospital geral e no psiquiátrico ele deixa transparecer a supremacia daquele sobre este, onde o modelo do hospital geral se reflete no trabalho em psiquiatria

"Sabe que o paciente no hospital clínico chegou, vai fazer uma cirurgia, vai fazer um tratamento, vai sarar e vai voltar à sua vida normal, né? (...) mas aqui você sabe que dificilmente você vai chegar a um tratamento de sucesso (...) $)^{\text {D1 }}$.

“(...) a gente trabalha com algumas limitações, a gente traz muito do trabalho de um hospital clínico prá área, para o hospital psiquiátrico e a gente quer trabalhar no hospital psiquiátrico como se estivesse trabalhando no hospital clínico(...) ${ }^{\text {D2 }}$.

7. A interação do enfermeiro com o paciente psiquiátrico é apontada como uma necessidade para a melhoria da assistência de enfermagem

"Muitas vezes a gente desempenha o papel de conselheira, de conversar, sentar ao lado do paciente (...) a gente procura conversar com os pacientes e

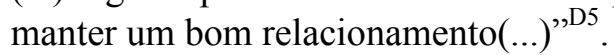

“(...) embora a gente às vezes, perceba que há uma necessidade de interagir melhor com o paciente de... né? de se abrir com ele é... uma interação no colher informações, no dialogar", ${ }^{\text {D2 }}$.

“(...) eu tenho assim um pouco de dificuldade nesse sentido, de definir o que que é uma queixa real que o paciente tá sentindo, ou se é só pra chamar a atenção, que é só da psicose dele" ${ }^{\text {"D7 }}$.

(...) Às vezes a gente com uma conversa a gente consegue até chegar à algum lugar, você consegue acalmar o paciente" ${ }^{\text {,D1 }}$.

\section{Analisando o Conteúdo das Informações}

Neste momento passaremos a análise das informações obtidas das falas, onde pretendemos estar discutindo os conteúdos que emergiram relacionando-os com outros estudos que já estiveram apontando as questões que emergiram através dos discursos dos entrevistados. Nossa postura foi de tentar estar compreendendo estas informações considerando que seus autores - os enfermeiros - fazem parte de toda uma estrutura que sustenta suas práticas.

Quando o enfermeiro coloca que trabalhar em psiquiatria é estar atendendo situações de emergência, deixa transparecer que não há um planejamento ou uma metodologia que ele use para orientar o seu trabalho, sendo a sua ação improvisada, pois quando os problemas vão aparecendo vamos respondendo a eles. Isso nos parece que aponta para a falta de clareza quanto aos objetivos do trabalho em enfermagem psiquiátrica, pois como aponta FERREIRA (1994, p. 16):

“(...) me decido a não improvisar quando tenho um objetivo em vista e estou interessado em alcançálo. Se não quero chegar à nada, se quero somente passar o tempo, viver o momento presente, deixarme surpreender pelo que for ocorrendo, vou improvisando todas as minhas ações ao sabor dos ventos".

Contudo, gostaríamos de destacar que esta falta de clareza dos objetivos não deve ser encarada como um "pecado" do enfermeiro enquanto ser "individual", pois ROCHA (1994, p. 102) coloca que:

"Ser o coordenador de um grupo que presta assistência direta em uma instituição psiquiátrica é uma tarefa complexa. E a dificuldade tende a aumentar quando essa instituição não tem um projeto e uma referência teórica definido".

Desta forma, não apenas o enfermeiro tem que estar consciente do que pretende, mas também a instituição precisa ter claro o que pretende ou o que acredita ser o trabalho do enfermeiro. O que acabamos vendo, explicitado ou não, nos projetos institucionais é o enfermeiro apenas presente na equipe em função de exigências legais e não como uma peça importante na assistência ao ser em sofrimento psíquico. Aí fica difícil estabelecer diálogo e tentar ocupar um espaço que só existe teoricamente.

$\mathrm{Na}$ segunda unidade temática analisada, o enfermeiro aponta para a sua dificuldade em definir qual seja o seu papel dentro da enfermagem psiquiátrica.

A indefinição de papéis, a crise de identidade do 
profissional enfermeiro está presente, não só na especialidade enfermagem psiquiátrica, mas neste espaço ela é gritante, o que acaba resultando, no nosso ponto de vista, em uma sensação de nulidade. Se estamos no serviço ele funciona, se não estamos ele também funciona.

A exigência legal da presença do enfermeiro nas unidades psiquiátricas, abriu um campo de atuação a este profissional, porém não garantiu sua efetiva inserção naquele espaço. A mudança na lei, não correspondeu a uma mudança na prática.

O enfermeiro constata com indignação sua deficiência frente ao seu trabalho, mas daí a estabelecer que causas poderiam estar afetando este trabalho, ele já não consegue mais avançar. Com relação a este contexto, um enfermeiro justifica dizendo que "nós paramos muito pouco prá questionar, prá questionar, prá analisar, prá ver o que a gente tá querendo com a psiquiatria"D3 ${ }^{\text {. Sem }}$ dúvida, o espaço para reflexão contribuiria muito para estar desvendando esta realidade e, parece que estes enfermeiros não estão conseguindo este espaço ou não há essa consciência por todo o grupo ou, ainda, não há interesse por parte da chefia da instituição em incentivar isso.

Quanto ao campo de pesquisa, na tentativa de compreender um pouco mais o que estes enfermeiros estão identificando como uma indefinição de papéis da enfermagem psiquiátrica, a instituição trata-se de uma instituição total, onde, há restrições no ir e vir dos pacientes, no uso de pertences e objetos pessoais e uma disciplina bastante rígida quanto aos horários para todas as atividades. Neste cenário, o enfermeiro entra como intermediário entre os que ditam as normas e os que devem executar - pacientes e pessoal de nível médio. Assim, ele sente a necessidade de um trabalho que esteja voltado para o paciente, mas está orientado por um poder instituído ao qual não consegue se rebelar. É uma situação dada, acabada e não há o que contestar. Mas e daí? Será que, se o enfermeiro quiser ele não reverte este quadro?

ROCHA (1994), com relação à isso, relata três situações bastante semelhantes onde tentou-se reverter esta situação através da mudança de posicionamento exclusivamente da enfermagem e nada se conseguiu. A ruptura estaria acontecendo quando a equipe multiprofissional e as chefias tivessem os mesmos objetivos e se o foco do trabalho fosse o homem que passa por um período que necessita de ajuda - o que parece ainda longe nesta área.

$\mathrm{Na}$ terceira temática, aparece a relação do enfermeiro com a equipe técnica como uma indefinição de espaços. A enfermagem aparece como desvalorizada frente aos outros profissionais, ou, quando tenta estabelecer um relacionamento com o paciente, isso significa estar entrando no espaço do outro profissional: "Tem a questão, a equipe, a gente não quer entrar no espaço do outro, né? É... porque determinada coisa, a gente acha que é do psicólogo ou acha que é do terapeuta ocupacional, outra coisa é coisa específica do psiquiatra, ou, às vezes, do serviço social”, ${ }^{\prime}$. Na realidade isso é um reflexo da indefinição do que seja o papel do enfermeiro e da desvalorização deste profissional, que talvez possa ser atribuída ao fato de ser um trabalho manual, não reconhecido, sendo expressão da divisão social e técnica do trabalho.

STEFANELLI et al. (1985, p. 128) tratam da enfermagem psiquiátrica e da equipe multiprofissional, apontando que:

"Dados de observação e informações obtidas junto a profissionais que atuam em equipe multiprofissional, em unidade de internação psiquiátrica, indicam atuação aleatória dos membros da equipe, não havendo funções estabelecidas para cada elemento".

Também apareceu nos discursos dos enfermeiros, na quarta temática, a relação da formação acadêmica com a sua prática profissional e nos seus discursos o enfermeiro vai dizer que há uma deficiência entre o que é ensinado na graduação e o que os espera no campo de trabalho ou no mercado. Esta distância estaria acontecendo devido à desvinculação da teoria ou do espaço institucional acadêmico com a realidade dos hospitais psiquiátricos, como nos enriquece este discurso: "Eu sinto que a faculdade não me preparou prá ser uma enfermeira em hospital psiquiátrico" $"$.

Esta unidade está apontando um problema que parece geral nesta área onde, conforme trabalho de outros autores, como MARCOLAN (1996, p. 65-6), a realidade não é diferente, onde em seu estudo, ao falar sobre a formação profissional, diz que:

“(...) algumas escolas de enfermagem dão ênfase maior ao ensino do relacionamento terapêutico nos cursos de graduação, sendo que na prática é difícil implementar o mesmo nas atividades de enfermagem devido às condições de trabalho. Por outro lado, ocorrem dificuldades na prestação de assistência quando o enfermeiro se defronta com alterações de comportamento e quadros patológicos, devido à falta de embasamento teórico prático que deveria ter sido dado na graduação".

ROCHA (1994, p. 109), falando na formação e no espaço de trabalho do enfermeiro que atua em psiquiatria diz que:

"Nossos entrevistados haviam considerado ter sido bom o ensino de enfermagem psiquiátrica, no curso 
de graduação. No entanto, ao iniciarem as atividades no hospital, não tinham clareza quanto ao seu papel. De onde se depreende, principalmente, que o ensino da graduação, mesmo sendo bom, é fundamentalmente técnico e, no que toca à enfermagem psiquiátrica não é suficiente".

Um ponto comum entre esses dois autores é a questão de que o enfermeiro não se especializou para trabalhar em psiquiatria e isso seria um fator agravante nessa área, que o enfermeiro acaba indo trabalhar nessa área por acaso, quase nunca sendo uma opção refletida. Como coloca um dos entrevistados, a disciplina de enfermagem psiquiátrica não chamava a atenção e agora é enfermeira nesta área.

Outro enfermeiro entrevistado aponta para este aspecto, atribuindo esta falha à formação teórica que é desvinculada da realidade do trabalho no hospital psiquiátrico, "a formação, talvez, foi um tanto teórica, talvez é desvinculada do que acontece nos hospitais psiquiátricos... eu penso que a realidade de que a faculdade passa e o que a gente faz no hospital psiquiátrico, o espaço que dão prá gente, talvez exista uma pequena diferença entre eles" ${ }^{\text {D2 } 2}$. Isto vai ao encontro do que MARCOLAN (1996) colocou anteriormente, com a falta de interligação teoria-prática.

A desvinculação do que se passa no espaço acadêmico e a prática assistencial, contudo não é privilégio da disciplina de enfermagem psiquiátrica. Há que se pensar uma aproximação real entre o que ensinamos e o que realmente se executa, ou apontar aos alunos os caminhos que viabilizem aquela aproximação. Como fazer isso?

$\mathrm{Na}$ quinta temática o enfermeiro coloca que as questões administrativas estão presentes na maioria das atividades que ele desenvolve no seu trabalho na enfermagem psiquiátrica. Nos discursos dos enfermeiros, quando eles fazem referência a este tema, é no sentido de que esta atividade acaba tendo um peso maior ou se sobressaindo às outras: "em psiquiatria eu vejo isso, se preocupar com a falta ou não de funcionários, com escala (...)"D3 . O fato do enfermeiro estar se apegando as atividades administrativas parece estar sendo determinado pelo fato de que este é um espaço conquistado e definido, ao passo que assumir outros comportamentos implica em desmistificar a imagem do gerente, o privilégio de quem comanda, "manda", organiza.

$\mathrm{Na}$ verdade, por conta da divisão do trabalho, cabe ao enfermeiro a função de capataz, de sentinela dos donos das instituições, intermediário entre os donos da força de trabalho e os trabalhadores diretos. Esta função administrativa surge para dar conta desta relação conflituosa de trabalho, sendo esse um dos aspectos desse contexto.

Um outro aspecto é o refúgio, como aponta
ROCHA (1994), do enfermeiro nas funções burocráticas, por falta de identificação com outra função ou, poderíamos dizer, pela pobreza na definição do seu fazer na enfermagem psiquiátrica. $\mathrm{O}$ enfermeiro não foi preparado para atuar neste espaço, ele não tem uma função definida, não está claro o seu papel, então ele vai assumir questões burocráticas que é um espaço já dado onde sua atuação não vai gerar conflitos pois é só organizar o espaço para a atuação de outros profissionais.

Os enfermeiros psiquiátricos, "sem a definição do seu papel, declinam as funções de ensino e supervisão, refugiando-se na burocracia" (ROCHA, 1994, p.114).

AGUIAR (1995), no entanto, coloca sobre a existência de uma corrente afirmando que o papel do enfermeiro em psiquiatria seria o desenvolvimento do relacionamento terapêutico. Porém, contrapondo-se a esse discurso outros autores vão apontar:

"Para a existência de uma enfermagem dedicada ao repasse da ideologia institucional ao paciente no interior dos hospitais psiquiátricos de moldes asilares. $\mathrm{O}$ cumprimento das normas burocráticas coloca-se como objetivo central do trabalho da enfermeira, no entanto, no plano do discurso, a enfermeira situa a sua prática no atendimento das necessidades humanas básicas dos pacientes e no desenvolvimento do relacionamento interpessoal" (AGUIAR, 1995, p. 20-1).

Nas condições em que se encontra o paciente hospitalizado, segundo os enfermeiros estudados, seria impossível estar pensando no relacionamento terapêutico como método de trabalho do enfermeiro, pois, as condições concretas não existem neste espaço para que ele se efetive. A relação do enfermeiro com o paciente é uma relação disciplinar onde para manter a ordem o enfermeiro acaba usando a autoridade que a posição lhe confere. Nestas condições o fator confiança não existe, $o$ que aborta a interação efetiva profissional-paciente.

Na sexta temática que convergiu dos discursos, o enfermeiro traz a questão da supremacia do trabalho do enfermeiro do hospital geral sobre o trabalho do enfermeiro no hospital psiquiátrico, onde as características daquele espaço tendem a ser transpostas a este como se as realidades fossem idênticas: “(...) a gente quer trabalhar no hospital psiquiátrico como se estivesse trabalhando no hospital clínico" ${ }^{\text {D2 }}$.

$\mathrm{Na}$ falta de um fazer definido o enfermeiro executa o que lhe parece correto ou o que se aproxima mais das ações que já está acostumado a realizar. Ao transpor para o hospital psiquiátrico as atividades do hospital clínico, o enfermeiro estará se ocupando com as medicações, banhos, curativos, entre outras atividades mais específicas do enfermeiro de hospital geral e vai se 
distanciando de qualquer interação possível com o paciente. Também o que poderia estar conduzindo à este posicionamento, seria o modelo de atenção à saúde ao qual o enfermeiro se enquadra. Podemos dizer que se trata de um modelo centrado na consulta médica, na psicofarmacologia e nos cuidados com o corpo. Se acreditamos neste conceito de atenção à saúde ou se estamos fortemente vinculados a ele - e parece que é a nossa realidade - então, a nossa prática será bastante centrada na atenção médico-hospitalar e teremos grandes dificuldades de ousar outras alternativas. Este é sem dúvida, um fator à ser considerado.

No discurso do enfermeiro apontando que a atenção no hospital clínico terá resolutividade: “(...) o paciente no hospital clínico chegou, vai fazer uma cirurgia, um tratamento, vai sarar e vai voltar à sua vida normal ou vai evoluir para um óbito"D1, me parece que corrobora a visão de atenção à saúde centrada no espaço hospitalar e na figura do médico, nos equipamentos, técnicas, procedimentos.

Outra coisa que nos é apontada é a descrença na possibilidade do paciente voltar a sua vida normal. Conforme nos refere o enfermeiro entrevistado, alguns poucos diagnósticos são passíveis de reversão. Será que este dado não nos aponta a falência deste tipo de atendimento? Se este tipo de atenção atende trezentas pessoas em média, o tempo todo, e isso não acaba em um resultado positivo, então, qual a validade desse nosso trabalho? Como sobrevive uma instituição que não dá conta do seu objetivo, que seria devolver o indivíduo ao seu espaço, em condições de voltar à produzir, ao mundo do trabalho?

Na sétima e última unidade, surgiu a questão da interação do enfermeiro com o paciente. Nos discursos dos enfermeiros não apareceu referência explícita de que esta interação seja o relacionamento terapêutico que é discutido por alguns autores, exceto em um dos discursos onde ele delineia como necessário o relacionamento terapêutico entre o enfermeiro e o paciente. Apesar desse apontamento ele relativisa dizendo que tem feito isso de forma assistemática, informal, o que nos autoriza a entender que não se trata do relacionamento terapêutico proposto pelos teóricos dessa área.

Quando o enfermeiro deixa transparecer a necessidade da interação com o paciente, esta interação é pensada de forma aleatória, parece que é sentida a necessidade de estar conversando com o paciente quando isso for necessário, como nos diz esse discurso: “(...) muitas vezes a gente desempenha o papel de conselheira, de conversar, sentar ao lado do paciente (...) não quer dizer que em todos os momentos eu vou estar sentando ao lado do paciente, conversando com ele"D5 . Contudo, a proposta do relacionamento terapêutico como método de trabalho do enfermeiro em psiquiatria, seria uma intervenção planejada, discutida, de interação do enfermeiro com a equipe multiprofissional e com o paciente.

Desta forma, podemos dizer que os enfermeiros entrevistados, em sua maioria, não reconhecem o relacionamento terapêutico como metodologia de trabalho e nem fazem referência a ele como atividade de que tenham algum conhecimento, estes conceitos parecem não terem sido incorporados pelos enfermeiros entrevistados.

\section{CONSIDERAÇÕES FINAIS}

Entender um pouco mais sobre enfermagem psiquiátrica e estar tentando contribuir com este ramo do saber do enfermeiro, foi a pretensão deste trabalho. Esta preocupação estava perpassada pela inquietação frente à situação adversa do indivíduo em sofrimento psíquico, sendo que, nesse momento, esta inquietação é amenizada um pouco a partir de uma maior compreensão do que determina aquela situação adversa.

No entanto, continuamos defendendo que a dignidade, a humanidade deve ser preservada ou devolvida a estes indivíduos, frutos de inúmeras situações, entre elas, a organização do processo produtivo que colabora na determinação da doença e em seguida exclui este doente, pois o mesmo já não é mais útil ao sistema.

Os fundamentos históricos sobre os quais se organizou a psiquiatria institucional no Brasil possibilitou compreender a manifestação, até hoje de um caráter cerceador, disciplinador do espaço psiquiátrico. Neste espaço, a enfermagem se organiza, desenvolvendo um trabalho de controle do ambiente, garantindo a ordem e as regras necessárias à manutenção deste espaço.

$\mathrm{Na}$ análise dos dados coletados, observamos que os atores desta pesquisa tinham dificuldade em estar colocando claramente qual o seu papel ao atuar em psiquiátrica, sendo que esta dificuldade advém de não se ter visível qual é este papel.

Em função dessa dificuldade percebemos que o enfermeiro acaba se ocupando em tarefas ditas administrativas, sendo este um papel mais definido e que ele já executa desde que ingressou no mercado de trabalho. Contudo, ele sente necessidade de estar repensando este seu fazer, pois percebe que o trabalho com o ser em sofrimento psíquico tem especificidades que esta função administrativa deixa de contemplar.

Quanto a este aspecto há que se considerar ainda que esta função é o que se espera do enfermeiro, enquanto agente organizador, saneador do espaço, que faz com que as coisas funcionem a contento. Não se espera que o enfermeiro esteja no trabalho direto com os pacientes, pois para este contato temos os auxiliares e atendentes. 
Nos encontramos aqui na divisão social e técnica do trabalho, onde o enfermeiro é o gerenciador e o resto da equipe executa, sendo esta uma relação de trabalho concreta deste processo de trabalho, onde a superação não é fruto da vontade individual, que se o enfermeiro simplesmente quiser tudo vai melhorar.

Acreditamos que a superação desta situação estaria na discussão aberta de toda a equipe definindo explicitamente a função de cada um. Mesmo que ao final se chegue a um acordo de que o enfermeiro deve continuar sendo alheio ao trabalho com o paciente, mas que isto esteja claro, assumido, documentado.

Outro aspecto a se considerar neste estudo, foi a emergência da temática formação acadêmica e sua relação com o espaço prático, apontando uma distância entre os dois momentos, gerando insegurança no enfermeiro ao atuar na psiquiátrica.

A necessidade de aproximação entre o espaço acadêmico e o espaço prático não é denunciada somente nesta área e os caminhos para sua efetivação não estão claros. Como investir por exemplo nos conteúdos de saúde mental, se o espaço para o enfermeiro ainda é na maioria o espaço hospitalar? Seria suficiente o ensino ao enfermeiro de como estabelecer um relacionamento terapêutico se no espaço hospitalar ele não tem contato direto com o paciente? Sistematizar a assistência através do processo de enfermagem seria a solução?

As reflexões que conseguimos realizar neste trabalho trazem limitações e deixam questões em aberto, onde a prática estudada nos mostrou questões de ordem política, social e econômica, que apenas a vontade individual, isolada, não tem condições de fazer cair por terra. Contudo, desejamos que este estudo seja referencial para posteriores análises e reflexões, que ajudem a modificar a assistência de enfermagem ao ser humano em sofrimento psíquico.

\section{NURSING IN THE CARE TO INDIVIDUALS IN PSYCHICAL SUFFERING}

Nursing care to the human being in psychical suffering is the theme of this investigation, developed in a psychiatric hospital, in the west region of the Paraná State. This is a qualitative research with the aim of finding out nurses' understanding about their work in psychiatric nursing. Authors used open interview to all the nurses of the institution. Then, data were grouped in thematic unities and analysed through the analysis of the content.

KEY WORDS: nursing care, psychiatric nursing

\section{LA ENFERMERÍA EN LA ASISTENCIA AL INDIVIDUO EN SUFRIMIENTO PSIQUICO}

La asistencia de enfermería al ser humano en sufrimiento psíquico es el tema de esta pesquisa, desenvuelta en un hospital psiquiátrico en la región oeste de Paraná. Es una pesquisa cualitativa con el objetivo de detectar la comprensión que tiene el enfermero acerca de su hacer en la enfermería psiquiátrica. Utilizamos la entrevista abierta abarcando todos los enfermeros de la institución, donde los datos fueron reunidos en unidades temáticas y analizados con la técnica de análisis de contenido.

TÉRMINOS CLAVES: asistencia de enfermería, enfermería psiquiátrica

\section{REFERÊNCIAS BIBLIOGRÁFICAS}

\section{AGUIAR, M.E. A reinvenção do ser enfermagem} no cotidiano da casa de saúde Anchieta e Núcleos de Atenção Psicossocial. São Paulo, 1995. 155p. Dissertação (Mestrado) - Escola de Enfermagem, Universidade de São Paulo.

02. BARDIN, L. Análise de conteúdo. Lisboa: Edições 70, 1991.

03. FERREIRA, F.W. Planejamento sim e não. 13. ed. Rio de Janeiro: Paz e Terra, 1994.

04. FRAGA, M.N.O. A prática da enfermagem psiquiátrica: subordinação e resistência. São Paulo: Cortez, 1993.
05. MARCOLAN, J.F. Opinião dos enfermeiros que atuam em enfermagem psiquiátrica e em saúde mental no município de São Paulo sobre suas ações. São Paulo, 1996. 233p. Dissertação (Mestrado) - Escola de Enfermagem, Universidade de São Paulo.

06. ROCHA, R.M. Enfermagem psiquiátrica: que papel é esse?. Rio de Janeiro: Instituto Franco Basaglia/ Te corá, 1994.

07. STEFANELLI, M.C. et al. A enfermagem psiquiátrica e a equipe multiprofissional. Rev. Esc. Enfermagem USP, São Paulo, v.19, n.29, p.127134, 1985. 